\title{
Best proximity points and fixed points for p-summing maps
}

Mihaela Ancuța Petric ${ }^{1}$ and Boyan Zlatanov ${ }^{2 *}$

* Correspondence:

bzlatanov@gmail.com

${ }^{2}$ Department of Mathematics and

Informatics, Plovdiv University, 24

"Tzar Assen" str., 4000 Plovdiv,

Bulgaria

Full list of author information is

available at the end of the article

\section{Abstract}

We have found a new type of a contractive condition that ensures the existence and uniqueness of fixed points and best proximity points in uniformly convex Banach spaces. We provide some examples to validate our results. These results generalize some known results from fixed point theory.

AMS Subject Classification: 47H10; 54H25.

Keywords: fixed point, cyclical operator, contractive condition, best proximity point, uniformly convex Banach space

\section{Introduction}

A fundamental result in fixed point theory is the Banach contraction principle. One kind of a generalization of the Banach contraction principle is the notation of cyclical maps [1]. Fixed point theory is an important tool for solving equations $T x=x$ for mappings $T$ defined on subsets of metric spaces or normed spaces. Because a non-self mapping $T: A \rightarrow B$ does not necessarily have a fixed point, one often attempts to find an element $x$ which is in some sense closest to $T x$. Best proximity point theorems are relevant in this perspective. The notation of best proximity point is introduced in [2]. This definition is more general than the notation of cyclical maps, in sense that if the sets intersect, then every best proximity point is a fixed point. A sufficient condition for the uniqueness of the best proximity points in uniformly convex Banach spaces is given in [2]. It turns out that many of the contractive-type conditions which are investigated for fixed points ensure the existence of best proximity points. Some results of this kind are obtained in [3-6]. It is interesting that in all the investigated conditions for the existence of best proximity the distances between sets are equal. We have found a new type of condition which warrants the existence and the uniqueness of the best proximity points for sets with different distances between them. This new type of a map we have called a $p$-summing map. We have also shown that this new type of map, the $p$-summing map, if considered not as a cyclical map, has a unique fixed point.

\section{Preliminary results}

In this section, we give some basic definitions and concepts which are useful and related to the best proximity points. Let $(X,\|\cdot\|)$ be a Banach space. Define a distance between two subsets $A, B \subset X$ by $\operatorname{dist}(A, B)=\inf \{\|x-y\|: x \in A, y \in B\}$.

(c) 2012 Petric and Zlatanov; licensee Springer. This is an Open Access article distributed under the terms of the Creative Commons Attribution License (http://creativecommons.org/licenses/by/2.0), which permits unrestricted use, distribution, and reproduction in any medium, provided the original work is properly cited. 
Definition 2.1. [2,5] Let $A_{1}, A_{2}, \ldots, A_{p}$ be non-empty subsets of a Banach space $(X,\|\cdot\|)$ and let $T: \bigcup_{i=1}^{p} A_{i} \rightarrow \bigcup_{i=1}^{p} A_{i}$. The map $T$ is called a $p$-cyclic contraction, if it satisfies the following conditions:

(1) $T\left(A_{i}\right) \subseteq A_{i+1} ; 1 \leq i \leq p$, where $A_{p+i}=A_{i}$;

(2) For some $k \in(0,1)$ the inequality $\|T x-T y\| \leq k\|x-y\|+(1-k) \operatorname{dist}\left(A_{i}, A_{i+1}\right)$ holds for any $x \in A_{i}, y \in A_{i+1}, 1 \leq i \leq p$. A point $\xi \in A_{i}$ is said to be a best proximity point of $T$ in $A_{i}$ if $\|\xi-T \xi\|=\operatorname{dist}\left(A_{i}, A_{i+1}\right)$.

Definition 2.1 is given for two sets $A_{1}$ and $A_{2}$ in [2], and for $p$-sets in [5].

It is proved in [5], that if a map is a $p$-cyclic contraction, then it has best proximity points for every set $A_{i}, 1 \leq i \leq p$.

We will use the following two lemmas, established in [2], to proving the uniqueness of the best proximity points.

Lemma 2.1. [2] Let $A$ be a non-empty, closed, convex subset, and B be a non-empty, closed subset of a uniformly convex Banach space. Let $\left\{x_{n}\right\}_{n=1}^{\infty}$ and $\left\{z_{n}\right\}_{n=1}^{\infty}$ be sequences in $A$ and $\left\{y_{n}\right\}_{n=1}^{\infty}$ be a sequence in $B$ satisfying:

(1) $\lim _{n \rightarrow \infty}\left\|z_{n}-y_{n}\right\|=\operatorname{dist}(A, B)$;

(2) for every $\varepsilon>0$ there exists $N_{0} \in \mathbb{N}$, such that for all $m>n \geq N_{0}$, $\left\|x_{n}-y_{n}\right\| \leq$ dist $(A, B)+\varepsilon$.

Then for every $\varepsilon>0$, there exists $N_{1} \in \mathbb{N}$, such that for all $m>n>N_{1}$, holds $\left\|x_{m}-z_{n}\right\| \leq \varepsilon$.

Lemma 2.2. [2] Let $A$ be a non-empty, closed, convex subset, and $B$ be a non-empty, closed subset of a uniformly convex Banach space. Let $\left\{x_{n}\right\}_{n=1}^{\infty}$ and $\left\{z_{n}\right\}_{n=1}^{\infty}$ be sequences in $A$ and $\left\{y_{n}\right\}_{n=1}^{\infty}$ be a sequence in B satisfying:

(1) $\lim _{n \rightarrow \infty}\left\|x_{n}-y_{n}\right\|=\operatorname{dist}(A, B)$;

(2) $\lim _{n \rightarrow \infty}\left\|z_{n}-y_{n}\right\|=\operatorname{dist}(A, B)$;

then $\lim _{n \rightarrow \infty}\left\|x_{n}-z_{n}\right\|=0$

Theorem 2.1. [7] Let $(X,\|\cdot\|)$ be a Banach space and $F: X \rightarrow R \cup\{+\infty\}$ be a lower semicontinuous function on $X$ that is bounded from below and not identically equal to $+\infty$. Fix $\varepsilon>0$ and a point $x_{0} \in X$, such that

$$
F\left(x_{0}\right) \leq \varepsilon+\inf \{F(x): x \in X\} .
$$

Then there exists a point $v \in X$, such that $\left\|x_{0}-v\right\| \leq 1$ and $F(v) \leq F\left(x_{0}\right)$, and for any $w \neq v$ there holds the inequality

$$
F(v) \leq F(w)+\varepsilon\|v-w\| .
$$

\section{Main results}

Let $(X,\|\cdot\|)$ be a Banach space and $A_{i} \in X$. We denote $P=\operatorname{dist}\left(A, A_{2}\right)+\operatorname{dist}\left(A_{2}, A_{3}\right)+$ $\operatorname{dist}\left(A_{3}, A_{1}\right)$.

Definition 3.1. Let $A_{i}, i=1,2,3$ be subsets of a uniformly convex Banach space ( $X$, $\|\cdot\|)$. A map $T: \bigcup_{i=1}^{3} A_{i} \rightarrow \bigcup_{i=1}^{3} A_{i}$ will be called a 3-cyclic summing contraction if it satisfies the following conditions: 
(1) $T\left(A_{i}\right) \subseteq A_{i+1}$, for every $i=1,2,3$ and by $A_{4}$ we understand $A_{1}$;

(2) Let there exists $k \in(0,1)$, such that for any $x_{i} \in A_{i}, i=1,2,3$ there holds the inequality

$$
\begin{aligned}
& \left\|T x_{1}-T x_{2}\right\|+\left\|T x_{2}-T x_{3}\right\|+\left\|T x_{3}-T x_{1}\right\| \\
& \quad \leq k\left(\left\|x_{1}-x_{2}\right\|+\left\|x_{2}-x_{3}\right\|+\left\|x_{3}-x_{1}\right\|\right)+(1-k) P
\end{aligned}
$$

Theorem 3.1. Let $A_{i}, i=1,2,3$ be closed, convex subsets of a uniformly convex Banach space $X$ and $T: \bigcup_{i=1}^{3} A_{i} \rightarrow \bigcup_{i=1}^{3} A_{i}$ is a 3-cyclic summing contraction. Then for any $i=1,2,3$ there exist unique best proximity points $z_{i} \in A_{i}$, such that for any $x \in A_{i}$ the sequence $\left\{T^{3 n} x\right\}_{n=1}^{\infty}$ converges to $z_{i}$. Moreover, $T^{j} z_{i}=z_{i+j}$ is a best proximity point in $A_{i+j}, j=1,2$ and $z_{i}$ is a fixed point of the map $T^{3}$.

Definition 3.2. Let $(X,\|\cdot\|)$ be a Banach space. A map $T: X \rightarrow X$ will be called a 3 -summing contraction if there exists $k \in(0,1)$, such that for any $x \neq y \neq z$ there holds the inequality

$$
\|T x-T y\|+\|T y-T z\|+\|T z-T x\| \leq k(\|x-y\|+\|y-z\|+\|z-x\|) .
$$

Let us mention that any contraction map $T: X \rightarrow X$ is a 3-summing map, but obviously there are 3-summing maps that are not contractions. The requirement $x \neq y \neq z$ in Definition 3.2 is necessary because if we do not impose it, then if we take $y=z$ in (3.2) we will get the classical Banach contraction condition.

Theorem 3.2. Let $X$ be a Banach space and $T: X \rightarrow X$ be a 3-summing contraction. Then $T$ has a unique fixed point.

It is easy to define a $p$-summing contraction. Let us mention that all the results in Theorems 3.1 and 3.2 are true for a $p$-summing contraction. Just for the sake of simplicity we decide to state them and to prove them for a 3-summing contraction.

\section{Auxiliary results}

Lemma 4.1. Let $A_{i}, i=1,2,3$ be closed, convex subsets of a uniformly convex Banach space $X$ and $T: \bigcup_{i=1}^{3} A_{i} \rightarrow \bigcup_{i=1}^{3} A_{i}$ be a 3 -cyclic summing contraction, then for any $x \in A_{i}$, $i=1,2,3$ the iterative sequence $\left\{T^{n} x\right\}_{n=1}^{\infty}$ satisfies

$$
\lim _{n \rightarrow \infty}\left(\left\|T^{n+3} x-T^{n+2} x\right\|+\left\|T^{n+2} x-T^{n+1} x\right\|+\left\|T^{n+1} x-T^{n+3} x\right\|\right)=P
$$

Proof. Let $x \in A_{i}$. By the chain of inequalities:

$$
\begin{aligned}
& \left\|T^{n+3} x-T^{n+2} x\right\|+\left\|T^{n+2} x-T^{n+1} x\right\|+\left\|T^{n+1} x-T^{n+3} x\right\| \\
& \leq k\left(\left\|T^{n+2} x-T^{n+1} x\right\|+\left\|T^{n+1} x-T^{n} x\right\|+\left\|T^{n} x-T^{n+2} x\right\|\right) \\
& +(1-k) P \\
& \leq k^{2}\left(\left\|T^{n+1} x-T^{n} x\right\|+\left\|T^{n} x-T^{n-1} x\right\|+\left\|T^{n-1} x-T^{n+1} x\right\|\right) \\
& +(1+k)(1-k) P \\
& \leq k^{3}\left(\left\|T^{n} x-T^{n-1} x\right\|+\left\|T^{n-1} x-T^{n-2} x\right\|+\left\|T^{n-2} x-T^{n} x\right\|\right) \\
& +\left(1+k+k^{2}\right)(1-k) P \\
& \leq k^{n+1}\left(\left\|T^{2} x-T x\right\|+\|T x-x\|+\left\|x-T^{2} x\right\|\right) \\
& +\left(1+k+\cdots+k^{n}\right)(1-k) P \\
& =k^{n+1}\left(\left\|T^{2} x-T x\right\|+\|T x-x\|+\left\|x-T^{2} x\right\|\right)+\left(1-k^{n+1}\right) P
\end{aligned}
$$


and the fact that $T^{n+1} x, T^{n+2} x$ and $T^{n+3} x$ belong to different sets $A_{i}, i=1,2,3$, we get the inequality

$$
\begin{aligned}
P & =\operatorname{dist}\left(A_{1}, A_{2}\right)+\operatorname{dist}\left(A_{2}, A_{3}\right)+\operatorname{dist}\left(A_{3}, A_{1}\right) \\
& \leq\left\|T^{n+3} x-T^{n+2} x\right\|+\left\|T^{n+2} x-T^{n+1} x\right\|+\left\|T^{n+1} x-T^{n+3} x\right\| \\
& \leq k^{n+1}\left(\left\|T^{2} x-T x\right\|+\|T x-x\|+\left\|x-T^{2} x\right\|\right)+\left(1-k^{n+1}\right) P
\end{aligned}
$$

and the proof follows because $\lim _{n \rightarrow \infty} k^{n}=0$.

Lemma 4.2. Let $A_{i}, i=1,2,3$ be closed, convex subsets of a uniformly convex Banach space $X$ and $T: \bigcup_{i=1}^{3} A_{i} \rightarrow \bigcup_{i=1}^{3} A_{i}$ be a 3-cyclic summing contraction, then for any $x \in A_{i}$ the inequality

$$
\left\|T^{3 n+1} x-T^{3 n} x\right\| \leq k^{3 n-1}(\alpha(x)-P)+\operatorname{dist}\left(A_{i}, A_{i+1}\right)
$$

holds, where

$$
\alpha(x)=\left\|T^{2} x-T x\right\|+\|T x-x\|+\left\|x-T^{2} x\right\|
$$

Proof. If $x \in A_{i}$, then $T^{3 n} x \in A_{i}$ and $T^{3 n+1} x \in A_{i+1}$. By the proof of Lemma 4.1 we have

$$
\begin{aligned}
\| T^{3 n+1} x- & T^{3 n} x \|+P-\operatorname{dist}\left(A_{i}, A_{i+1}\right) \\
& \leq\left\|T^{3 n+1} x-T^{3 n} x\right\|+\left\|T^{3 n} x-T^{3 n-1} x\right\|+\left\|T^{3 n-1} x-T^{3 n+1} x\right\| \\
& \leq k^{3 n-1}\left(\left\|T^{2} x-T x\right\|+\|T x-x\|+\left\|x-T^{2} x\right\|\right)+\left(1-k^{3 n-1}\right) P
\end{aligned}
$$

thus

$$
\left\|T^{3 n+1} x-T^{3 n} x\right\| \leq \operatorname{dist}\left(A_{i}, A_{i+1}\right)+k^{3 n-1}(\alpha(x)-P) .
$$

Corollary 4.1. Let $A_{i}, i=1,2,3$ be closed, convex subsets of a uniformly convex Banach space $X$ and $T: \bigcup_{i=1}^{3} A_{i} \rightarrow \bigcup_{i=1}^{3} A_{i}$ be a 3-cyclic summing contraction, then for any $x \in A_{i}$ there holds

$$
\lim _{n \rightarrow \infty}\left\|T^{3 n+1} x-T^{3 n} x\right\|=\operatorname{dist}\left(A_{i}, A_{i+1}\right) .
$$

Lemma 4.3. Let $A_{i}, i=1,2,3$ be closed, convex subsets of a uniformly convex Banach space $X$ and $T: \bigcup_{i=1}^{3} A_{i} \rightarrow \bigcup_{i=1}^{3} A_{i}$ be a 3-cyclic summing contraction, then for any $x, y \in A_{i}$ the inequality

$$
\left\|T^{3 n+1} x-T^{3 n+3} y\right\| \leq k^{3 n-1}(\alpha(x, y)-P)+\operatorname{dist}\left(A_{i}, A_{i+1}\right)
$$

holds, where

$$
\alpha(x, y)=\left\|x-T^{2} y\right\|+\left\|T^{2} y-T y\right\|+\|T y-x\|
$$

Proof. If $x, y \in A_{i}$, then $T^{3 n} y \in A_{i}$ and $T^{3 n+1} x \in A_{i+1}$. By the proof of Lemma 4.1 we have

$$
\begin{aligned}
\| T^{3 n+1} x- & T^{3 n+3} y \|+P-\operatorname{dist}\left(A_{i}, A_{i+1}\right) \\
& \leq\left\|T^{3 n+1} x-T^{3 n+3} y\right\|+\left\|T^{3 n+3} y-T^{3 n+2} y\right\|+\left\|T^{3 n+2} y-T^{3 n+1} x\right\| \\
& \leq k^{3 n+1}\left(\left\|x-T^{2} y\right\|+\left\|T^{2} y-T y\right\|++\|T y-x\|\right)+\left(1-k^{3 n+1}\right) P
\end{aligned}
$$


thus

$$
\left\|T^{3 n+1} x-T^{3 n+3} y\right\| \leq \operatorname{dist}\left(A_{i}, A_{i+1}\right)+k^{3 n+1}(\alpha(x, y)-P) .
$$

Corollary 4.2. Let $A_{i}, i=1,2,3$ be closed, convex subsets of a uniformly convex Banach pace $X$ and $T: \bigcup_{i=1}^{3} A_{i} \rightarrow \bigcup_{i=1}^{3} A_{i}$ be a 3-cyclic summing contraction, then for any $x, y \in A_{i}$ there holds

$$
\lim _{n \rightarrow \infty}\left\|T^{3 n+1} x-T^{3 n+3} y\right\|=\operatorname{dist}\left(A_{i}, A_{i+1}\right) .
$$

The following lemma can be proved in a similar fashion.

Lemma 4.4. Let $A_{i}, i=1,2,3$ be closed, convex subsets of a uniformly convex Banach space $X$ and $T: \bigcup_{i=1}^{3} A_{i} \rightarrow \bigcup_{i=1}^{3} A_{i}$ be a 3-cyclic summing contraction, then for any $x \in A_{i}$ and for any $k \in \mathbb{N}$ there hold:

$$
\begin{aligned}
& \lim _{n \rightarrow \infty}\left\|T^{3 n+1} x-T^{3 n \pm 3} x\right\|=\operatorname{dist}\left(A_{i}, A_{i+1}\right), \\
& \lim _{n \rightarrow \infty}\left\|T^{3 n} x-T^{3 n \pm 3} x\right\|=0, \\
& \lim _{n \rightarrow \infty}\left\|T^{3 n+k+1} x-T^{3 n+k \pm 3} x\right\|=\operatorname{dist}\left(A_{i+k}, A_{i+1+k}\right), \\
& \lim _{n \rightarrow \infty}\left\|T^{3 n+k} x-T^{3 n+k \pm 3} x\right\|=0,
\end{aligned}
$$

Lemma 4.5. Let $A_{i}, i=1,2,3$ be closed, convex subsets of a uniformly convex Banach space $X$ and $T: \bigcup_{i=1}^{3} A_{i} \rightarrow \bigcup_{i=1}^{3} A_{i}$ be a 3-cyclic summing contraction. If for some $x \in A_{i}, i=1,2,3$, the iterative sequence $\left\{T^{3 n} x\right\}_{n=1}^{\infty}$ has a cluster point $z$, then $z$ is a best proximity point of $T$ in $A_{i}$.

Proof. Let $\lim _{j \rightarrow \infty} T^{3 n_{j}} x=z$. Then by the continuity of the function $f(u)=\|u-v\|$, for fixed $v \in X$ it it follows that $\|z-T z\|=\lim _{j \rightarrow \infty}\left\|T^{3 n_{j}} x-T z\right\|$. We will prove first that

$$
\lim _{j \rightarrow \infty}\left\|T^{3 n_{j}-1} x-z\right\|=\lim _{j \rightarrow \infty}\left\|T^{3 n_{j}-1} x-T^{3 n_{j}} x\right\| .
$$

By the triangle inequality:

$$
0 \leq\left|\left\|T^{3 n_{j}-1} x-z\right\|-\left\|T^{3 n_{j}-1} x-T^{3 n_{j}} x\right\|\right| \leq\left\|T^{3 n_{j}} x-z\right\|
$$

it follows that

$$
\lim _{j \rightarrow \infty}\left(\left\|T^{3 n_{j}-1} x-z\right\|-\left\|T^{3 n_{j}-1} x-T^{3 n_{j}} x\right\|\right)=0
$$

If we take $k=2$ in (4.6) we get

$$
\lim _{j \rightarrow \infty}\left\|T^{3 n_{j}+3} x-T^{3 n_{j}-1} x\right\|=\operatorname{dist}\left(A_{i}, A_{i+2}\right) .
$$


For any $x \in A_{i}$ the inclusions $T^{3 n_{j}} x \in A_{i}, T^{3 n_{j}-1} x \in A_{i+2}$ hold. Then by the inequality

$$
\operatorname{dist}\left(A_{i}, A_{i+2}\right) \leq\left\|T^{3 n_{j}-1} x-T^{3 n_{j}} x\right\| \leq\left\|T^{3 n_{j}-1} x-T^{3 n_{j}+3} x\right\|+\left\|T^{3 n_{j}+3} x-T^{3 n_{j}} x\right\|,
$$

and the equalities (4.5) and (4.11) we get

$$
\lim _{j \rightarrow \infty}\left\|T^{3 n_{j}-1} x-T^{3 n_{j}} x\right\|=\operatorname{dist}\left(A_{i}, A_{i+2}\right) .
$$

Now by (4.10) and (4.12) we found that (4.8) holds true.

We apply consecutively (4.8) to obtain the next chain of inequalities:

$$
\begin{aligned}
\| z- & T z\|+\| T z-T^{2} z\|+\| T^{2} z-z \| \\
= & \lim _{j \rightarrow \infty}\left(\left\|T^{3 n_{j}} x-T z\right\|+\left\|T z-T^{2} z\right\|+\left\|T^{2} z-T^{3 n_{j}} x\right\|\right) \\
\leq & k \lim _{j \rightarrow \infty}\left(\left\|T^{3 n_{j}-1} x-z\right\|+\|z-T z\|+\left\|T z-T^{3 n_{j}-1} x\right\|\right)+(1-k) P \\
= & k \lim _{j \rightarrow \infty}\left(\left\|T^{3 n_{j}-1} x-T^{3 n_{j}} x\right\|+\left\|T^{3 n_{j}} x-T z\right\|+\left\|T z-T^{3 n_{j}-1} x\right\|\right) \\
& +(1-k) P \\
\leq & k^{2} \lim _{j \rightarrow \infty}\left(\left\|T^{3 n_{j}-2} x-T^{3 n_{j}-1} x\right\|+\left\|T^{3 n_{j}-1} x-z\right\|+\left\|z-T^{3 n_{j}-2} x\right\|\right) \\
& +(1+k)(1-k) P \\
= & k^{2} \lim _{j \rightarrow \infty}\left(\left\|T^{3 n_{j}-2} x-T^{3 n_{j}-1} x\right\|+\left\|T^{3 n_{j}-1} x-T^{3 n_{j}} x\right\|\right. \\
& \left.+\left\|T^{3 n_{j}} x-T^{p n_{j}-2} x\right\|\right)+(1+k)(1-k) P \\
\leq & k^{3} \lim _{j \rightarrow \infty}\left(\left\|T^{3 n_{j}-3} x-T^{3 n_{j}-2} x\right\|+\left\|T^{3 n_{j}-2} x-T^{3 n_{j}-1} x\right\|\right. \\
& \left.+\left\|T^{3 n_{j}-1} x-T^{p n_{j}-3} x\right\|\right)+\left(1+k+k^{2}\right)(1-k) P \\
= & k^{3} P+\left(1-k^{3}\right) P=P .
\end{aligned}
$$

Since $z \in A_{i}$ it follows that $T z \in A_{i+1}, T^{2} z \in A_{i+2}$ and hence

$$
P-\operatorname{dist}\left(A_{i}, A_{i+1}\right)=\operatorname{dist}\left(A_{i+1}, A_{i+2}\right)+\operatorname{dist}\left(A_{i+2}, A_{i}\right) \leq\left\|T z-T^{2} z\right\|+\left\|T^{2} z-z\right\| .
$$

Consequently by (4.13) we obtain

$$
\|z-T z\|+P-\operatorname{dist}\left(A_{i}, A_{i+1}\right) \leq\|z-T z\|+\left\|T z-T^{2} z\right\|+\left\|T^{2} z-z\right\| \leq P
$$

and therefore we get $\|z-T z\| \leq \operatorname{dist}\left(A_{i}, A_{i+1}\right)$. The opposite inequality $\|z-T z\| \geq$ $\operatorname{dist}\left(A_{i}, A_{i+1}\right)$ is obvious and hence we conclude that $\|z-T z\|=\operatorname{dist}\left(A_{i}, A_{i+1}\right)$. Thus $z$ is a best proximity point of $T$ in $A_{i}$.

Lemma 4.6. Let $A_{i}, i=1,2,3$ be closed, convex subsets of a uniformly convex Banach space $X$ and $T: \bigcup_{i=1}^{3} A_{i} \rightarrow \bigcup_{i=1}^{3} A_{i}$ be a 3-cyclic summing contraction. If for some $x \in A_{i}, i=1,2,3$, the iterative sequence $\left\{T^{3 n} x\right\}_{n=1}^{\infty}$ has a cluster point $z$, then $z$ is a fixed point for $T^{3}$.

Proof. Let $\lim _{j \rightarrow \infty} T^{3 n_{j}} x=z$. Then from the continuity of the function $f(u)=\|u-v\|$, for fixed $v \in X$ it follows that $\left\|z-T^{4} z\right\|=\lim _{j \rightarrow \infty}\left\|T^{3 n_{j}} x-T^{4} z\right\| \quad$ and $\left\|z-T^{5} z\right\|=\lim _{j \rightarrow \infty}\left\|T^{3 n_{j}} x-T^{5} z\right\|$. 
We will prove first that

$$
\lim _{j \rightarrow \infty}\left\|T^{3 n_{j}-4} x-z\right\|=\lim _{j \rightarrow \infty}\left\|T^{3 n_{j}-4} x-T^{3 n_{j}} x\right\| .
$$

By the triangle inequality:

$$
0 \leq\left|\left\|T^{3 n_{j}-4} x-z\right\|-\left\|T^{3 n_{j}-4} x-T^{3 n_{j}} x\right\|\right| \leq\left\|T^{3 n_{j}} x-z\right\|
$$

it follows that

$$
\lim _{j \rightarrow \infty}\left(\left\|T^{3 n_{j}-4} x-z\right\|-\left\|T^{3 n_{j}-4} x-T^{3 n_{j}} x\right\|\right)=0 .
$$

For any $x \in A_{i}$ the inclusions $T^{3 n_{j}} x \in A_{i}, T^{3 n_{j}-4} x \in A_{i+2}$ hold and we can write the inequalities

$$
\begin{aligned}
\operatorname{dist}\left(A_{i}, A_{i+2}\right) & \leq\left\|T^{3 n_{j}-4} x-T^{3 n_{j}} x\right\| \\
& \leq\left\|T^{3 n_{j}-4} x-T^{3 n_{j}-1} x\right\|+\left\|T^{3 n_{j}-1} x-T^{3 n_{j}+3} x\right\|+\left\|T^{3 n_{j}+3} x-T^{3 n_{j}} x\right\| .
\end{aligned}
$$

From (4.7), (4.5), and (4.11) it follows that

$$
\lim _{j \rightarrow \infty}\left\|T^{3 n_{j}-4} x-T^{3 n_{j}} x\right\|=\operatorname{dist}\left(A_{i}, A_{i+2}\right)
$$

Now by (4.16) and (4.18) we found that (4.14) holds true. We will omit the proof that

$$
\lim _{j \rightarrow \infty}\left\|T^{3 n_{j}-5} x-z\right\|=\lim _{j \rightarrow \infty}\left\|T^{3 n_{j}-5} x-T^{3 n_{j}} x\right\|,
$$

because it is similar to the above one.

We apply consecutively (4.14), (4.8), and (4.19) to obtain the next chain of inequalities:

$$
\begin{aligned}
\| z- & T^{4} z\|+\| T^{4} z-T^{5} z\|+\| T^{5} z-z \| \\
= & \lim _{j \rightarrow \infty}\left(\left\|T^{3 n_{j}} x-T^{4} z\right\|+\left\|T^{4} z-T^{5} z\right\|+\left\|T^{5} z-T^{3 n_{j}} x\right\|\right) \\
\leq & k \lim _{j \rightarrow \infty}\left(\left\|T^{3 n_{j}-1} x-T^{3} z\right\|+\left\|T^{3} z-T^{4} z\right\|+\left\|T^{4} z-T^{3 n_{j}-1} x\right\|\right) \\
& +(1-k) P \\
\leq & k^{4} \lim _{j \rightarrow \infty}\left(\left\|T^{3 n_{j}-4} x-z\right\|+\|z-T z\|+\left\|T z-T^{3 n_{j}-4} x\right\|\right) \\
& +\left(1-k^{4}\right) P \\
= & k^{4} \lim _{j \rightarrow \infty}\left(\left\|T^{3 n_{j}-4} x-T^{3 n_{j}} x\right\|+\left\|T^{3 n_{j}} x-T z\right\|+\left\|T z-T^{3 n_{j}-4} x\right\|\right) \\
& +\left(1-k^{4}\right) P \\
\leq & k^{5} \lim _{j \rightarrow \infty}\left(\left\|T^{3 n_{j}-5} x-T^{3 n_{j}-1} x\right\|+\left\|T^{3 n_{j}-1} x-z\right\|+\left\|z-T^{3 n_{j}-5} x\right\|\right) \\
& +\left(1-k^{5}\right) P \\
= & k^{5} \lim _{j \rightarrow \infty}\left(\left\|T^{3 n_{j}-5} x-T^{3 n_{j}-1} x\right\|+\left\|T^{3 n_{j}-1} x-T^{3 n_{j}} x\right\|\right. \\
& \left.+\left\|T^{3 n_{j}} x-T^{3 n_{j}-5} x\right\|\right)+\left(1-k^{4}\right) P \\
\leq & k^{6} \lim _{j \rightarrow \infty}\left(\left\|T^{3 n_{j}-6} x-T^{3 n_{j}-2} x\right\|+\left\|T^{3 n_{j}-2} x-T^{3 n_{j}-1} x\right\|\right. \\
& \left.+\left\|T^{3 n_{j}-1} x-T^{3 n_{j}-6} x\right\|\right)+\left(1-k^{6}\right) P \\
= & k^{6} P+\left(1-k^{6}\right) P=P .
\end{aligned}
$$


By $z \in A_{i}$ it follows that $T^{4} z \in A_{i+1}, T^{5} z \in A_{i+2}$ and hence

$$
P-\operatorname{dist}\left(A_{i}, A_{i+1}\right)=\operatorname{dist}\left(A_{i+1}, A_{i+2}\right)+\operatorname{dist}\left(A_{i+2}, A_{i}\right) \leq\left\|T^{4} z-T^{5} z\right\|+\left\|T^{5} z-z\right\| .
$$

Consequently by (4.20) we obtain

$$
\left\|z-T^{4} z\right\|+P-\operatorname{dist}\left(A_{i}, A_{i+1}\right) \leq\left\|z-T^{4} z\right\|+\left\|T^{4} z-T^{5} z\right\|+\left\|T^{5} z-z\right\| \leq P .
$$

and therefore we get $\left\|z-T^{4} z\right\| \leq \operatorname{dist}\left(A_{i}, A_{i+1}\right)$. The opposite inequality $\left\|z-T^{4} z\right\| \geq$ $\operatorname{dist}\left(A_{i}, A_{i+1}\right)$ is obvious and therefore it follows that $\|z-T z\|=\operatorname{dist}\left(A_{i}, A_{i+1}\right)$. Now by Lemma 4.5 we get that

$$
\left\|z-T^{4} z\right\|=\|z-T z\|=\operatorname{dist}\left(A_{i}, A_{i+1}\right)
$$

and from the uniform convexity of $X$ it follows that $T^{4} x=T x$.

By the inequality

$$
\begin{aligned}
& \left\|T^{4} z-T^{3} z\right\|+\left\|T^{3} z-T^{2} z\right\|+\left\|T^{2} z-T z\right\| \\
& \quad=\left\|T^{4} z-T^{3} z\right\|+\left\|T^{3} z-T^{2} z\right\|+\left\|T^{2} z-T^{4} z\right\| \\
& \quad \leq k\left(\left\|T^{3} z-T^{2} z\right\|+\left\|T^{2} z-T z\right\|+\left\|T z-T^{3} z\right\|\right)+(1-k) P \\
& \quad=k\left(\left\|T^{3} z-T^{2} z\right\|+\left\|T^{2} z-T z\right\|+\left\|T^{4} z-T^{3} z\right\|\right)+(1-k) P
\end{aligned}
$$

we get

$$
(1-k)\left\|T^{4} z-T^{3} z\right\|+(1-k)\left(P-\operatorname{dist}\left(A_{i}, A_{i+1}\right)\right) \leq(1-k) P,
$$

i.e. $\left\|T^{4} z-T^{3} z\right\| \leq \operatorname{dist}\left(A_{i}, A_{i+1}\right)$. By the obvious inequality $\left\|T^{4} z-T^{3} z\right\| \geq \operatorname{dist}\left(A_{i}, A_{i+1}\right)$ it follows that $\left\|T^{4} z-T^{3} z\right\|=\operatorname{dist}\left(A_{i}, A_{i+1}\right)$. Now from

$$
\left\|z-T^{4} z\right\|=\left\|T^{3} z-T^{4} z\right\|=\operatorname{dist}\left(A_{i}, A_{i+1}\right)
$$

and the uniform convexity of $X$ it follows that $T^{3} z=z$.

Lemma 4.7. If $T$ is a 3-summing contraction then $T$ is continuous.

Proof. Let fix $x_{0} \in X$ and let $\left\{y_{n}\right\}_{n=1}^{\infty}$ and $\left\{z_{n}\right\}_{n=1}^{\infty}$ be two sequences, that are convergent to $x_{0}$. Then for any $\varepsilon>0$ there is $n_{0} \in \mathbb{N}$, such that for every $n \geq n_{0}$ there holds $\|$ $x-y_{n}\|+\| y_{n}-z_{n}\|+\| z_{n}-y_{n} \|<\varepsilon$. By the inequalities

$$
\begin{aligned}
\left\|T x_{0}-T y_{n}\right\| & \leq\left\|T x_{0}-T y_{n}\right\|+\left\|T y_{n}-T z_{n}\right\|+\left\|T z_{n}-T x_{0}\right\| \\
& \leq k\left(\left\|x_{0}-y_{n}\right\|+\left\|y_{n}-z_{n}\right\|+\left\|z_{n}-x_{0}\right\|\right)<\varepsilon
\end{aligned}
$$

it follows that $T$ is continuous at $x_{0}$.

\section{Proof of main results}

Proof of Theorem 3.1. First we will show that for any $x \in A_{i}$ the sequence $\left\{T^{3 n} x\right\}_{n=1}^{\infty}$ is convergent, i.e., it is enough to prove that the sequence $\left\{T^{3 n} x\right\}_{n=1}^{\infty}$ is a Cauchy sequence.

Claim 5.1. For any $\varepsilon>0$ there exists $n_{0}$, such that for any $m>n \geq n_{0}$ there holds the inequality

$$
\left\|T^{3 m} x-T^{3 n+1} x\right\|+\left\|T^{3 n+1} x-T^{3 n+2} x\right\|+\left\|T^{3 n+2} x-T^{3 m} x\right\|<P+\varepsilon
$$


Proof of Claim 5.1. Suppose the contrary, i.e., there is $\varepsilon>0$ such that for every $k \in \mathbb{N}$ there are $m_{k}>n_{k} \geq k$ so that

$$
\left\|T^{3 m_{k}} x-T^{3 n_{k}+1} x\right\|+\left\|T^{3 n_{k}+1} x-T^{3 n_{k}+2} x\right\|+\left\|T^{3 n_{k}+2} x-T^{3 m_{k}} x\right\| \geq P+\varepsilon .
$$

Choose $m_{k}$ to be the smallest integer satisfying (5.22). Now from Lemma 4.5 we have that

$$
\lim _{k \rightarrow \infty}\left\|T^{3 m_{k}} x-T^{3 m_{k}-3} x\right\|=0
$$

and by

$$
\begin{gathered}
P+\varepsilon \leq\left\|T^{3 m_{k}} x-T^{3 n_{k}+1} x\right\|+\left\|T^{3 n_{k}+1} x-T^{3 n_{k}+2} x\right\|+\left\|T^{3 n_{k}+2} x-T^{3 m_{k}} x\right\| \\
\leq\left\|T^{3 m_{k}} x-T^{3 m_{k}-3} x\right\|+\left\|T^{3 m_{k}-3} x-T^{3 n_{k}+1} x\right\| \\
\quad+\left\|T^{3 n_{k}+1} x-T^{3 n_{k}+2} x\right\|+\left\|T^{3 n_{k}+2} x-T^{3 m_{k}} x\right\|
\end{gathered}
$$

we get

$$
P+\varepsilon \leq \lim _{k \rightarrow \infty}\left(\left\|T^{3 m_{k}} x-T^{3 n_{k}+1} x\right\|+\left\|T^{3 n_{k}+1} x-T^{3 n_{k}+2} x\right\|+\left\|T^{3 n_{k}+2} x-T^{3 m_{k}} x\right\|\right) \leq P+\varepsilon .
$$

Thus

$$
\lim _{k \rightarrow \infty}\left(\left\|T^{3 m_{k}} x-T^{3 n_{k}+1} x\right\|+\left\|T^{3 n_{k}+1} x-T^{3 n_{k}+2} x\right\|+\left\|T^{3 n_{k}+2} x-T^{3 m_{k}} x\right\|\right)=P+\varepsilon
$$

Now from the triangular inequality we have

$$
\begin{aligned}
\| T^{3 m_{k}} x- & T^{3 n_{k}+1} x\|+\| T^{3 n_{k}+1} x-T^{3 n_{k}+2} x\|+\| T^{3 n_{k}+2} x-T^{3 m_{k}} x \| \\
\leq & \left\|T^{3 m_{k}} x-T^{3 m_{k}+3} x\right\|+\left\|T^{3 m_{k}+3} x-T^{3 n_{k}+4} x\right\| \\
& +\left\|T^{3 n_{k}+4} x-T^{3 n_{k}+1} x\right\| \\
& +\left\|T^{3 n_{k}+1} x-T^{3 n_{k}+4} x\right\|+\left\|T^{3 n_{k}+4} x-T^{3 n_{k}+5} x\right\| \\
& +\left\|T^{3 n_{k}+5} x-T^{3 n_{k}+2} x\right\| \\
+ & +\left\|T^{3 n_{k}+2} x-T^{3 n_{k}+5} x\right\|+\left\|T^{3 n_{k}+5} x-T^{3 m_{k}+3} x\right\| \\
& +\left\|T^{3 m_{k}+3} x-T^{3 m_{k}} x\right\|
\end{aligned}
$$

and by Lemma 4.4, taking a limit in (5.23) and applying condition (3.1) three times we get we get

$$
\begin{aligned}
\lim _{k \rightarrow \infty}\left(\| T^{3 m_{k}} x-\right. & \left.T^{3 n_{k}+1} x\|+\| T^{3 n_{k}+1} x-T^{3 n_{k}+2} x\|+\| T^{3 n_{k}+2} x-T^{3 m_{k}} x \|\right) \\
\leq & \lim _{k \rightarrow \infty}\left(\left\|T^{3 m_{k}+3} x-T^{3 n_{k}+4} x\right\|+\left\|T^{3 n_{k}+4} x-T^{3 n_{k}+5} x\right\|\right. \\
& \left.+\left\|T^{3 n_{k}+5} x-T^{3 m_{k}+3} x\right\|\right) \\
\leq & k^{3} \lim _{k \rightarrow \infty}\left(\left\|T^{3 m_{k}} x-T^{3 n_{k}+1} x\right\|+\left\|T^{3 n_{k}+1} x-T^{3 n_{k}+2} x\right\|\right. \\
& \left.+\left\|T^{3 n_{k}+2} x-T^{3 m_{k}} x\right\|\right)+\left(1-k^{3}\right) P
\end{aligned}
$$

i.e.

$$
P+\varepsilon \leq k^{3}(P+\varepsilon)+\left(1-k^{3}\right) P,
$$

which is a contradiction and Claim 5.1 is proved. 
Now by Claim 5.1 we have that for any $\varepsilon>0$ there is $n_{0}$, such that

$$
\left\|T^{3 m} x-T^{3 n+1} x\right\|<\operatorname{dist}\left(A_{i}, A_{i+1}\right)+\varepsilon
$$

for every $m>n \geq n_{0}$ and by Corollary 4.1 and Lemma 2.1 we have that the sequence $\left\{T^{3 n} x\right\}_{n=1}^{\infty}$ is a Cauchy sequence. Thus $\lim _{n \rightarrow \infty} T^{3 n} x=z$ and $z$ is a best proximity point of $T$ in $A_{i}$.

For the next proof we will follow the idea in [8], how to use a variational principle to prove a fixed point theorem.

Proof of Theorem 3.2. Let us define the function $F: X \rightarrow \mathbb{R}$ by

$$
F(x)=\|T x-x\|+\left\|T^{2} x-T x\right\|+\left\|T^{2} x-x\right\| .
$$

Since by Lemma 4.7 the function $T$ is continuous and so is $F$. It is easy to see that $F$ is bounded form below and not identically $+\infty$. Choose $\varepsilon_{0}>0$, such that $k+\varepsilon<1$. There exists $x_{0} \in X$, such that $F\left(x_{0}\right)<\varepsilon_{0}+\inf \{F(x): x \in X\}$, because $F$ is continuous and bounded from below. Therefore, we can apply Theorem 2.1. By Theorem 2.1 there is $v \in X$, such that $\left\|x_{0}-v\right\| \leq 1$ and for every $w \in X$ there holds the inequality

$$
F(v) \leq F(w)+\varepsilon\|v-w\| .
$$

Suppose that $T$ does not have a fixed point then $F(v)>0$ for every $v \in X$. Put $w=$ $T v$. Then we get the inequality $F(v) \leq F(T v)+\varepsilon\|v-T v\|$, i.e.,

$$
\begin{aligned}
F(v) & =\|T v-v\|+\left\|T^{2} v-T v\right\|+\left\|T^{2} v-v\right\| \\
& \leq\left\|T^{2} v-T v\right\|+\left\|T^{3} v-T^{3} v\right\|+\left\|T^{3} v-T v\right\|+\varepsilon\|v-T v\| \\
& \leq k\left(\|T v-v\|+\left\|T^{2} v-T v\right\|+\left\|T^{2} v-v\right\|\right)+\varepsilon\|v-T v\| \\
& =(k+\varepsilon)\|T v-v\|+k\left(\left\|T^{2} v-T v\right\|+\left\|T^{2} v-v\right\|\right) .
\end{aligned}
$$

By the last chain of inequalities we get

$$
(1-k-\varepsilon)\|T v-v\|+(1-k)\left(\left\|T^{2} v-T v\right\|+\left\|T^{2} v-v\right\|\right) \leq 0,
$$

which is a contradiction and therefore $T v=v$.

Let us suppose that $T$ has two fixed points $x \neq y$. Let $z \in X$, be fixed and different from $x, y$. There is $s_{0} \in \mathbb{N}$, such that $k^{s_{0}}<\frac{\|x-y\|}{\|x-y\|+\|y-z\|+\|z-x\|}$. Then for any $s$ $\geq s_{0}$ by 3.2 we get

$$
\begin{aligned}
\|x-y\| & =\left\|T^{s} x-T^{s} y\right\| \leq\left\|T^{s} x-T^{s} y\right\|+\left\|T^{s} y-T^{s} z\right\|+\left\|T^{s} z-T^{s} x\right\| \\
& \leq k\left(\left\|T^{s-1} x-T^{s-1} y\right\|+\left\|T^{s-1} y-T^{s-1} z\right\|+\left\|T^{s-1} z-T^{s-1} x\right\|\right) \\
& \leq k^{2}(\|x-y\|+\|y-z\|+\|z-x\|),
\end{aligned}
$$

which is a contradiction and thus $T$ has a unique fixed point.

We would like to illustrate Theorem 3.1 with two example:

Example 5.1. Consider the Euclidian space $\left(\mathbb{R}_{2}^{3},\|\cdot\|_{2}\right)$, endowed with the Euclidian norm $\quad\|(x, y, z)\|_{2}=\sqrt{x^{2}+y^{2}+z^{2}}$. Let $X \subset \mathbb{R}_{2}^{3} \quad$ be $X=\{(x, y, z): x \in[4,5], y, z=0\}, Y \subset \mathbb{R}_{2}^{3}$ be $Y=\{(x, y, z): y \in[1,2], x, z=0\}, Z \subset \mathbb{R}_{2}^{3}$ be $Z=\{(x, y, z): z \in[1,2], x, y=0\}$. Define the 3-cyclic map $T: X \rightarrow Y, T: Y \rightarrow Z, T:$ 
$Z \rightarrow X$ by

$$
\begin{array}{ll}
T(x, 0,0)=\left(0, \frac{x}{8}+\frac{1}{2}, 0\right), & x \in[4,5] \\
T(0, y, 0)=\left(0,0, \frac{y}{8}+\frac{7}{8}\right), & y \in[1,2] \\
T(0,0, z)=\left(\frac{z}{8}+\frac{31}{8}, 0,0\right), & z \in[1,2] .
\end{array}
$$

It is easy to check that

$$
\begin{aligned}
& \max \left\{\sqrt{\left(\frac{x}{8}+\frac{1}{2}\right)^{2}+\left(\frac{y}{8}+\frac{7}{8}\right)^{2}}-\frac{1}{2} \sqrt{\left(x^{2}+y^{2}\right)}: x \in[4,5], y \in[1,2]\right\}=\sqrt{2}-\frac{\sqrt{17}}{2}, \\
& \max \left\{\sqrt{\left(\frac{x}{8}+\frac{1}{2}\right)^{2}+\left(\frac{z}{8}+\frac{31}{8}\right)^{2}}-\frac{1}{2} \sqrt{(x)^{2}+z^{2}}: x \in[4,5], z \in[1,2]\right\}=\frac{\sqrt{17}}{2}, \\
& \max \left\{\sqrt{\left(\frac{y}{8}+\frac{7}{8}\right)^{2}+\left(\frac{z}{8}+\frac{31}{8}\right)^{2}}-\frac{1}{2} \sqrt{\left(y^{2}+z^{2}\right)}: x \in[1,2], z \in[1,2]\right\}=\sqrt{17}-\frac{\sqrt{2}}{2} .
\end{aligned}
$$

Thus we get that for every $x \in X, y \in Y, z \in Z$ there holds the inequality:

$$
\|T x-T y\|_{2}+\|T y-T z\|_{2}+\|T z-T x\|_{2} \leq \frac{1}{2}\left(\|x-y\|_{2}+\|y-z\|_{2}+\|z-x\|_{2}\right)+\frac{1}{2} P,
$$

because $P=\operatorname{dist}(X, Y)+\operatorname{dist}(Y, Z)+\operatorname{dist}(Z, X)=2 \sqrt{17}+\sqrt{2}$. The distances between the three sets are different. The map $T$ is not a cyclical contraction. Indeed, there exists $\varepsilon_{0}, \delta_{0}>0$, such that for any $z, y \in\left[1,1+\delta_{0}\right]$ we have

$$
\|T z-T y\|_{2} \geq \sqrt{17}-\varepsilon_{0}>\sqrt{2}+\varepsilon_{0} \geq k\|z-\gamma\|_{2}+(1-k) \operatorname{dist}(Z, X) .
$$

Example 5.2. Consider the Banach space $\left(\mathbb{R}_{2}^{3},|\|\cdot\||\right)$, where $\||\cdot|\|=\|\cdot\|_{2}+\|\cdot\|_{1}$ and $\|(x, y, z)\|_{1}=|x|+|y|+|z|$. Let $X \subset \mathbb{R}_{2}^{3}$ be $X=\{(x, y, z): x \in[4,5], y, z=0\}$, $Y \subset \mathbb{R}_{2}^{3}$ be $Y=\{(x, y, z): y \in[1,2], x, z=0\}, Z \subset \mathbb{R}_{2}^{3}$ be $Z=\{(x, y, z): z \in[1,2], x, y=$ 0\}. Define the 3-cyclic map $T: X \rightarrow Y, T: Y \rightarrow Z, T: Z \rightarrow X$ by

$$
\begin{array}{ll}
T(x, 0,0)=\left(0, \frac{x}{8}+\frac{1}{2}, 0\right), & x \in[4,5] \\
T(0, y, 0)=\left(0,0, \frac{y}{8}+\frac{7}{8}\right), & y \in[1,2] \\
T(0,0, z)=\left(\frac{z}{8}+\frac{31}{8}, 0,0\right), & z \in[1,2] .
\end{array}
$$

It is easy to check for every $x \in X, y \in Y, z \in Z$ that

$$
\begin{gathered}
\max \left\{\||T x-T y|\|-\frac{1}{2}\||x-y|\|: x \in[4,5], y \in[1,2]\right\}=-\frac{1}{2}+\sqrt{2}-\frac{\sqrt{17}}{2} \\
\max \left\{\||T x-T z|\|-\frac{1}{2}\||x-z|\|: x \in[4,5], z \in[1,2]\right\}=\frac{5}{4}+\frac{\sqrt{17}}{2} \\
\max \left\{\||T y-T z|\|-\frac{1}{2}\||y-z|\|: y \in[1,2], z \in[1,2]\right\}=4+\sqrt{17}-\frac{\sqrt{2}}{2}
\end{gathered}
$$


and $P=2 \sqrt{17}+\sqrt{2}+12$. Therefore, there holds the inequality

$$
\||T x-T y|\|+\||T y-T z|\|+\||T z-T x|\| \leq \frac{1}{2}(\||x-y|\|+\||y-z|\|+\||z-x|\|)+\frac{1}{2} P .
$$

It remains to show that the space $\left(R^{3},\||\cdot|\|\right)$ is uniformly convex. Let us consider its dual space $\left(R^{3},\left.|| \cdot||\right|^{*}\right)$. The norm $\||\cdot|||$ is strictly convex, then $\||\cdot| \mid\|^{*}$ is Geteaux differentiable $[9,10]$. The space $\left(R^{3},|\|\cdot \mid\| * *)\right.$ is finite dimensional and therefore $\||\cdot|\|^{*}$ is uniformly Frechet differentiable and consequently ||$|\cdot|||$ is uniformly convex $[9,10]$.

The distances between the three sets are different. The map $T$ is not a cyclical contraction. Indeed, there exist $\varepsilon_{0}, \delta_{0}>0$, such that for any $z, y \in\left[1,1+\delta_{0}\right]$ we have

$$
\||T z-T y|\| \geq \sqrt{17}+5-\varepsilon_{0}>\sqrt{2}+2+\varepsilon_{0} \geq k\|z-\gamma\|+(1-k) \operatorname{dist}(Z, X) .
$$

\section{Acknowledgements}

The authors would like to express their thanks to the Associate Editor and to the referees for the valuable comments and suggestions for improving this paper. Boyan Zlatanov is partially supported by Plovdiv University "Paisii Hilendarski", NPD, Project NI11-FMI-004.

\section{Author details}

${ }^{1}$ Department of Mathematics and Computer Science, North University of Baia Mare, Victoriei 76, 430072 Baia Mare, Romania 2Department of Mathematics and Informatics, Plovdiv University, 24 "Tzar Assen" str., 4000 Plovdiv, Bulgaria

\section{Authors' contributions}

Both the authors contributed equally and significantly in writing this article. They read and approved the final manuscript.

\section{Competing interests}

The authors declare that they have no competing interests.

Received: 22 September 2011 Accepted: 21 May 2012 Published: 21 May 2012

\section{References}

1. Kirk, W, Srinivasan, P, Veeramani, P: Fixed points for mappings satisfying cyclical contractive conditions. Fixed Point Theory. 4, 79-189 (2003)

2. Eldred, A, Veeramani, P: Existence and convergence of best proximity points. J Math Anal Appl. 323(2), 1001-1006 (2006). doi:10.1016/j.jmaa.2005.10.081

3. Baria, C, Suzuki, T, Vetroa, C: Best proximity points for cyclic Meir - Keeler contractions. Nonlinear Anal: Theory Methods Appl. 69(11), 3790-3794 (2008). doi:10.1016/j.na.2007.10.014

4. Karpagam, S, Agrawal, S: Best proximity point theorems for p-cyclic Meir-Keeler contractions. Fixed Point Theory Appl 2009 (2009). Article ID 197308

5. Karpagam, S, Agrawal, S: Existence of best proximity points of P-cyclic contractions. Fixed Point Theory J. 13, 99-105 (2012)

6. Petric, M: Best proximity point theorems for weak cyclic Kannan contractions. pp. 145-154. Faculty of Sciences and Mathematics, University of Nis, Serbia (2011)

7. Ekeland, I: On the variational principle. J Math Anal Appl. 47, 324-353 (1974). doi:10.1016/0022-247X(74)90025-0

8. Ekeland, T: Nonconvex minimization problems. Bull Am Math Soc. 1(3), 443-474 (1979). doi:10.1090/S0273-0979-197914595-6

9. Fabian, F, Habala, P, Hajek, P, Montesinos, P, Pelant, J, Zizler, V: Functional Analysis and Infinite-Dimensional Geometry. Springer, New York (2001)

10. Deville, R, Godefroy, G, Zizler, V: Smoothness and renormings in Banach Spaces. Pitman Monographs 64. Pitman, New York (1993)

doi:10.1186/1687-1812-2012-86

Cite this article as: Petric and Zlatanov: Best proximity points and fixed points for $p$-summing maps. Fixed Point Theory and Applications 2012 2012:86. 